\title{
EL ITINERARIO DE JAIME II DE ARAGÓN EN LA CONQUISTA DEL REINO CASTELLANO DE MURCIA (1296-1301)
}

\author{
Juan Manuel DEL ESTAL GUTIÉRREZ
}

Universidad de Alicante

El desarrollo de este tema admite la posibilidad de dos tratamientos diferentes. Uno: el seguimiento documental, día a día, de las andanzas y quehacer del monarca, Jaime II de Aragón, a través de los documentos reales de su cancillería (Registros, Cartas Reales y Pergaminos) del quinquenio empleado en la conquista y sometimiento casi total del Reino castellano de Murcia (1296-1301).

$Y$ otro: el estudio y exposición de la importancia y necesidad historiográfica del mismo; la metodología y mecánica seguidas en su elaboración; y, por último, su especial interés y utilidad singular para el correcto seguimiento puntual de la campaña militar aragonesa antedicha. El camino por el que hemos optado ha sido el de la fusión de entrambos extremos apuntados, cuidando de subrayar en un amplio Anexo documental los sucesos de mayor relevancia e interés al respecto.

\section{IMPORTANCIA Y NECESIDAD DEL CITADO ITINERARIO}

EI ITINERARIO de Jaime II de Aragón viene constituyendo lamentablemente una laguna inexcusable en la historiografía medieval de aquella corona.

Es curioso constatar cómo Jaime $I I$, que fue uno de los monarcas más sobresalientes en la política territorial expansionista de la Casa de Aragón, por la conquista y anexión a la misma de los Reinos de Murcia y de Cerdeña, más los Ducados de Neopatria y Atenas, siga hasta la fecha todavía sin contar con la publicación de su propio Itinerario.

Y es aun más sorprendente todavía que no cuente siquiera con la publicación al 
menos de algún Itinerario parcial, como su propio padre, Pedro III el Grande, con el de sus Viajes a Berbería y Sicilia, y su mismo nieto, Pedro IV el Ceremonioso, con el Itinerario de su viaje a Cerdeña o el de antes de ceñir la corona, el Itinerario del Infante Pedro.

$\mathrm{Y}$ Jaime II de Aragón pudo haber sido muy bien objeto de numerosos Itinerarios parciales, como el correspondiente, por citar tan solo unos pocos, a la Conquista y anexión del reino castellano de Murcia a la corona de Aragón (1296-1304),tema que hoy ocupa la atención principal de este Congreso; o el de la Infeudación papal del reino de Cerdeña a Jaime II de Aragón por Bonifacio VIII (1297) y el de su Conquista ulterior (1324 y años siguientes) por su hijo el Infante D.Alfonso, gracias a la singular ayuda paterna armada; o el Itinerario de su viaje a Roma y firma del Tratado de Anagni (1297/98), con el papa Bonifacio VIII, Felipe IV de Francia y el rey de Nápoles, Carlos II de Anjou ${ }_{3}$ o el Itinerario de su expedición marítima a Sicilia, contra su rey, Federico III, su hermano, en cumplimiento de lo estipulado en el citado Tratado de Anagni, en el que Jaime II se comprometió a arrebatar el reino de Sicilia a su hermano y devolverlo a la Iglesia Romana, a cambio de la susodicha infeudación papal del reino de Cerdeña, periplo que ocupó bien catorce meses (1298/99) al monarca aragonés, aunque infructuosamente; $y$, por último, entre tantos otros posible Itinerarios parciales, el Itinerario de las negociaciones castallano-aragonesas en agosto del 1304 y mayo del 1305, encaminadas, como es sabido, a poner fin a la ya larga contienda armada entre ambas coronas, mediante el Fallo Arbitral de Torrellas y el Acuerdo de Elche.

Pero ninguno de los referidos períodos, así como otros muchos de su largo reinado (junio 1291-noviembre 1327), mereció hasta la fecha los honores ni siquiera de un Itinerario parcial y cuanto menos de su Itinerario total.

Jaime II continúa siendo todavía en lo concerniente a Itinerarios la gran excepción de los monarcas de la corona de Aragón. Ya que desde su abuelo, Jaime I el Conquistador, hasta su biznieto, Martín I el Humano, el último dinasta de la Casa de Barcelona, todos los soberanos de la misma cuentan con la publicación de su propio Itinerario, total o parcial, en el espacio de casi dos siglos (1213-1410).

La relación bibliográfica de los Itinerarios publicados de los monarcas de la Casa de Aragón, nos muestra con diafanidad evidente la inexplicable inexistencia del Itinerario de Jaime II entre los aparecidos.

Anotamos seguidamente los ITINERARIOS de los monarcas de la Casa de Aragón publicados hasta la fecha:

\section{Jaime I el Conquistador (1213-1276).}

MIRET I SANS, J., Itinerari del Rei en Jacme lo Conqueridor, Barcelona, 1918. GUAL CAMARENA, J.M. y ZAFRA, J., Aportaciones al Itinerario de Jaime I, X Congreso de Historia de la Corona de Aragón, II, Zaragoza, 1980, pp. 81-88.

\section{Pedro III el Grande (1276-1285).}

MIRET I SANS, J., «Viatges del'Infant en Pere, fill de Jaume I en 1268-1269», Butlletí 
del Centre Excursionista de Catalunya, XVIII, Barcelona, 1908.

MIRET I SANS, J, «Notes sobre l'expedició del Rei en Pere el Gran a Barbería, 1281-1282", Boletín de la Real Academia de Buenas Letras, XIV, Barcelona, 1914. SOLDEVILA, F., «Pere el Gran», Memories del Institut d'Estudis Catalans, IV, Barcelona, pp. 2-6.

\section{Alfonso III el Liberal (1285-1291).}

PARPAL MARQUÉS, J., «Itinerario que siguió Alfonso III de Aragón en la conquista de Menorca», Revista Menorca, Maó, 1898, pp. 134-136 (conquista año 1287). CARRERAS Y CANDI, F., «ltinerari del Rei N'Anfos II lo Liberal», Boletín de la Real Academia de Buenas Letras de Barcelona, X, Barcelona, 1931, pp. 61-83.

\section{Jaime II de Aragón (1291-1327).}

Todavía sin Itinerario.

\section{Alfonso IV el Benigno (1327-1335).}

MIRET I SANS, J., «ltinerario del Rey Alfonso III de Cataluña, IV de Aragón. El conquistador de Cerdeña", Boletín de la Real Academia de Buenas Letras de Barcelona, V, Año IX, Núm. 34, Barcelona, 1909, pp. 3-15, 57-71, 114-123.

\section{Pedro IV el Ceremonioso (1335-1387).}

GIMÉNEZ SOLER, A., «El viaje de Pedro IV a Cerdeña en 1354», Boletín de la Real Academia de Buenas Letras de Barcelona, V, Barcelona, 1909-1910, pp. 93, 171-199, 287-298, 521-524.

GIRONA I LLAGOSTERA, D., «Itinerari de l'Infant Pere (desprès Rei Pere III)», Estudis Universitaris Catalans, 18, Barcelona, 1933, pp. 336-355; 19, Barcelona, 1934, pp. 81-262.

Juan I el Cazador (1387-1396).

GIRONA I LLAGOSTERA, D., Itinerari de I'Infant En Joan, Actas y Memorias del III Congreso de la Corona de Aragón, Valencia, 1923.

GIRONA I LLAGOSTERA, D., «Itinerari del Rei En Joan I (1387-1396)», Estudis Universitaris Catalans, XIII-XV, Barcelona, 1928-1930. Extracto publicado aparte, Barcelona, 1931, p. 281.

\section{Martín I el Humano (1396-1410).}

GIRONA I LLAGOSTERA, D., «Itinerari del Rei En Martí (1396-1410)», Anuari de I'Institut d'Estudis Catalans, IV y V, Barcelona, 1911 y 1914. Edición en un solo volumen, Barcelona, 1916, en $251 \mathrm{pp}$.

A la vista de la relación historiográfica que antecede, acerca de los ITINERARIOS publicados hasta la fecha, concernientes a los monarcas aragoneses de la Casa de Barcelona, desde el 1313 al 1410 , se hace harto penosa y sorprendente la inexisten- 
cia del Itínerario correspondiente a Jaime II el Justo, monarca que tanto sobresalió en la política territorial expansionista, así marítima como terrestre, de la Corona de Aragón.

Pues ajustándonos tan solo al tema principal, que hoy atrae la atención de este Congreso de Jaime II setecientos años después (1296-1996), a él se debe fundamentalmente la Conquista y anexión del Reino castellano de Murcia a su corona, en el quinquenio del 1296 al 1301 y la Incorporación oficial definitiva de la región centroseptentrional de Alicante al Reino de Valencia, por la Sentencia Arbitral de Torrellas (1304) y el Acuerdo de Elche, el 1305, creándose en tal ocasión la Procuración General de Orihuela o Tierras del Reino de Valencia ultra Sexonam. Tierras que por cierto recibieron de la generosa mano de este monarca su propia Constitución o Carta Magna, el año 1308, por la que se regirían en lo sucesivo todos sus vecinos, al par que por los Furs Valencianos y sus propios privilegios, hasta la supresión borbónica de los mismos por el decreto de Nova Planta del $1707^{1}$.

Fueros que no podemos olvidar que refunden sustancialmente el Fuero Real y demás fueros que sucesivamente promulgara el Rey Alfonso $X$ el Sabio a favor del Reino de Murcia y correspondientes villas septentrionales de Alicante, Orihuela, Elche y Guardamar del Segura, al lado de los ya citados Furs Valencianos, más los cuantiosos privilegios reales de Jaime II emanados tan profusamente a favor de las mismas ${ }^{2}$.

Tales fueros reales constituyeron todos juntos como el cedazo o entramado legal, por el que se rigieron estas villas alicantinas, dentro ya del marco constitucional del reino de Valencia, en el que siguieron vigentes como el Llibre dels furs i Usatges d'Oriola i Alacant por espacio de casi cuatro siglos, hasta la promulgación borbónica antes citada del 1707.

Datos todos éstos que nos revelan ampliamente la importancia y necesidad de la elaboración del ITINERARIO de Jaime II de Aragón, en el período concerniente al menos al tema primordial de este Congreso, con referencia a la conquista e incorporación del Reino castellano de Murcia a la Corona de Aragón, durante los años en los

1 ESTAL, Juan Manuel del, Alicante de villa a ciudad (1252-1490). Colección documental del Medievo Alicantino (CODOMA) III, Alicante, 1990, pp. 34-43 y 285-289. ÍDEM, «El fuero y las = Constitutiones Regni Murcie = de Jaime II de Aragón, 1296-1301», Historia Medieval. Anales de la Universidad de Alicante, 8, Dpto. Hist. Medieval, Alicante, 1990/91, pp. 19-56, passim.

2 ESTAL, J.M. del, Conquista y anexión de la tierras de Alicante al Reino de Valencia por Jaime Il de Aragón (1296-1308), Alicante, CAPA, Núm. 87, 1982; ÍDEM, Libro de los primitivos privilegios de Alfonso $X$ el Sabio a Alicante. Estudio histórico-crítico y edición facsímil, Madrid, EDILAN, 1984; IDEM, Documentos inéditos de Alfonso $X$ el Sabio y de su hijo, el Infante D. Sancho. Estudio, transcripción y facsímiles, Alicante, 1984; ÍDEM, El Reino de Murcia bajo Aragón, 1296-1305. Corpus documental (CODOMA) I/1, Instituto Juan Gil Albert, Alicante, 1985; ÍDEM, I/2, Alicante, 1990; ÍDEM, CODOMA II, años 1305-1380, Universidad Alicante, edic. microficha, 1988; ÍDEM, "CARTA MAGNA O FUERO de Jaime II de Aragón a las villas de Orihuela, Alicante, Elche y Guardamar, (1308)", Alicante, Papeles Alicantinos, Núm. 30, Alicante, 1988; ÍDEM, “Orihuela de villa a ciudad». Compendio de una historia bicentenaria desde Alfonso el Sabio de Castilla al Rey Magnánimo, Alfonso V de Aragón, (1243/381437/38), Alicante, 1996. 
que más activamente se desarrolló la campaña militar aragonesa, desde la primavera, sobretodo, del 1296 a la segunda quincena de enero del año $1301^{3}$.

$Y$ a este período concreto nos ceñiremos fundamentalmente en esta Comunicación, añadiendo a modo de Apéndice final un extracto del Itinerario de Jaime II de Aragón, ceñido a los hechos más notables y salientes, de la referida campaña militar de conquista del reino castellano de Murcia.

\section{METODOLOGÍA Y MECÁNICA SEGUIDAS EN LA ELABORACIÓN DEL MISMO}

Con referencia a la metodología empleada en la composición de este ITINERARIO, correspondiente a la conquista y anexión del reino castellano de Murcia por Jaime Il a la corona de Aragón, queremos subrayar que, pese al elevado número de fuentes documentales, impresas, del reinado de este monarca, a primera vista numerosas, no son ni con mucho suficientes para la ejecución completa de dicho itinerario, por cuanto resultan bastante escasos los días calendados de ese período de los cinco años referidos (febrero 1296-enero 1301), viéndonos por ello obligados a recurrir por fuerza mayor a las fuentes manuscritas e inéditas, en las más de las veces.

Tan sólo con la ayuda de éstas nos ha sido posible acceder a la identificación mayoritaria de la datación crónica y tópica de las andanzas del monarca de Aragón en todos y cada uno de los días de su largo reinado, permitiéndonos situarlo con exactitud en el tiempo y lugar precisos. Tan complejo cometido nos ha sido realizable solamente a través de los Registros de cancillería principalmente, al lado del muy elevado número de Cartas y Pergaminos Reales, depositados prioritariamente en el Archivo de la Corona de Aragón (Barcelona), concernientes al período estudiado.

A estas fuentes manuscritas e inéditas citadas, hay que agregar otras, también numerosas y manuscritas, guardadas en no pocos archivos nacionales y extranjeros, regionales, catedralicios y municipales, en cuyos numerosos fondos hemos podido recabar los datos indispensables para la confección de un calendario crónico-tópico antes apuntado. Por cuanto se hace bien patente la masa asaz voluminosa de documentación manuscrita que hay que hojear y ojear doblemente, removiendo folios y ver y volver a ver una y más veces dicha documentación, existente en los diferentes archivos referidos, al objeto de conseguir la información deseada.

Entraña esta obra de auténtico matiz heurístico una tarea de investigación documental, tan ardua y laboriosa, que, con referencia a un Itinerario no parcial, sino total, de Jaime II de Aragón, al igual que ocurre con el Itinerario completo de Pedro IV el Ceremonioso, precisa de la dedicación casi de por vida de una sola persona, para poder llevarlo a cabo satisfactoriamente. Así lo expresaba un experimentado maestro en estas lides, hace ya más de medio siglo, en los siguientes términos: “D’altres, com els Itineraris de Jaume II i el de Pere III el Cerimoniós, la revisió de centenars de regis-

3 ESTAL, J.M. del, "Nuevos datos sobre la capitulación y conquista aragonesa de Lorca", (amplio anexo documental), Homenaje al Prof. D. JUAN TORRES FONTES, Universidad de Murcia, 1987, pp. 431-464, passim. 
tres i la recerca i compulsació de milers de documents exigeisen per cada un d'ells la labor de tota la vida (y prosigue explicitando un voto personal). Aixó no contrastant, és d'esperar que hi haurà estudiosos qui non dubtaran d'esmerçar llur treball abnegat en la confecció dels Itineraris dels nostres comtes-reis, qui manquen a la història integral de Catalunya» ${ }^{4}$.

Y transcurrido más de medio siglo, hemos de seguir confesando, apenados, que tanto Pedro IV como Jaime II de Aragón, a excepción de unos pocos años calendados del primero, continúan esperando todavía uno y otro la confección y publicación de su respectivo Itinerario completo y total.

Por todo ello, nos es muy grato poder comunicar a los estudiosos de Jaime II en este Congreso, que tenemos ya ultimado el Itinerario de Jaime II de Aragón (12911327), completo y presentado a la Institució Valenciana d'Estudis i Investigació (IVEI) de la Generalitat Valenciana y Diputación Provincial de Valencia, a la espera tan sólo de su pronta publicación.

Con referencia ahora a la mecánica y técnica personal que hemos seguido en la elaboración del referido Itinerario, así total como parcial, cual es el caso de este último en la presente Comunicación, se ha optado por el método más usual y práctico en esta clase de trabajos, teniendo en cuenta siempre la mayor comodidad y utilidad práctica del usuario habitual.

Se ha buscado por ello preferentemente brindar al lector en todo momento una visión sinóptica de los días del mes en cada página, con la indicación simultánea y sucesiva para cada día de la datación crónica y tópica a la vez, fuente documental de referencia y una breve regesta del documento utilizado ${ }^{5}$.

Habida cuenta de la no poca complejidad existente en la confección de un Itinerario real, hemos estimado útil y esclarecedor, explicar la mecánica concreta, que en nuestro caso particular, nos ha servido a efectos de comodidad y rapidez muy positivamente en trasladar al papel los resultados diarios de la consulta documental.

Así por ejemplo, antes de iniciar en el archivo la lectura de un determinado registro de cancillería, nos impusimos la tarea práctica de trazar en un folio para cada mes del año, en columnas paralelas descendentes, los datos correspondientes a la calendación romana en la primera; los referentes al día del mes y de la semana, en la segunda y tercera; la datación tópica, en la cuarta; la referencia documental, en la quinta y, por último, la regesta o resumen del documento citado, en la sexta columna.

Método que nos resultó muy práctico, por cierto, y cómodo de verdad, por obviarnos las molestias sin número de tener que trasladar en cada documento la datación romana a la moderna. Trabajo que se repetiría miles de veces, al tener que efectuar en cada momento el cálculo de los referidos traslados cronísticos. Y hay que observar que el reinado tan largo de Jaime II de Aragón alcanzó casi los 37 años de gobierno

4 GIRONA I LLAGOSTERA, Daniel, «Itinerari del Rei En Joan I, 1387-1396», Revista d'Estudis Universitaris Catalans, XIII-XV, Barcelona, 1928-1930 y extracto en separata, Barcelona, 1931, p. 4.

5 Una ejemplificación de lo dicho puede comprobarla el lector consultando el Anexo documental del Itinerario parcial con que concluye este trabajo. 
(junio 1291-noviembre 1327), que suman con creces la elevada cifra de los 13.000 días.

El folio en cuestión podría presentarse en forma similar al patrón siguiente:

AÑo 1296

\begin{tabular}{|c|c|c|c|c|c|}
\hline Calend. rom & abril & día sem. & Lugar & Ref ${ }^{\mathrm{a}} \mathrm{dtal}$. & Regesta \\
\hline $\begin{array}{l}\text { kls } \\
\text { aprilis }\end{array}$ & 1 & domingo & Valencia & ACA reg. 104 & $\begin{array}{l}\text { Jaime II dispone preparativos } \\
\text { conquista reino } \text { cast }^{\circ} \text { Murcia }\end{array}$ \\
\hline $\begin{array}{l}\text { pridie non. } \\
\text { aprilis }\end{array}$ & 4 & miérc & Valencia & r. 104 f. $1 \mathrm{~V}$ & Carta en igual sentido \\
\hline nonas apr. & 5 & jueves & Valencia & r. $104 \mathrm{f} .1 \mathrm{r}$ & Ídem \\
\hline $\begin{array}{l}\text { VI idus } \\
\text { aprilis }\end{array}$ & 8 & $\operatorname{dom}^{\circ}$ & Valencia & r. 104 f. $5 v-6 r$ & Ídem \\
\hline Idus apr. & 13 & viern & Valencia & r. 104 f. $17 \mathrm{v}$ & Ídem \\
\hline $\begin{array}{l}X V I I I \text { kls } \\
\text { madii }\end{array}$ & 14 & sab & Valencia & r. 104 f. $19 r$ & $\begin{array}{l}\text { Jaime II a su consejero real } \\
\text { sobre conqt }{ }^{\underline{a}} \text { reino Murcia }\end{array}$ \\
\hline $\begin{array}{l}X \mathrm{kls} \\
\text { madii }\end{array}$ & 22 & $\operatorname{dom}^{\circ}$ & Alicante & r. 340 f. $55 \mathrm{v}$ & $\begin{array}{l}\text { Jaime II somete castillo y } \\
\text { villa de Alicante }\end{array}$ \\
\hline $\begin{array}{l}\text { VI kls } \\
\text { madii }\end{array}$ & 26 & juev & $\begin{array}{l}\text { Guardamar } \\
\text { de Segura }\end{array}$ & r. 340 f. $6 r$ & $\begin{array}{l}\text { Jaime II ocupa el castillo y } \\
\text { lugar de Guardamar }\end{array}$ \\
\hline $\begin{array}{l}\text { Il kls } \\
\text { madii }\end{array}$ & 30 & lun & Almoradí & r. 340 f. $52 \mathrm{r}$ & $\begin{array}{l}\text { Conquista del lugar de } \\
\text { Almoradí }\end{array}$ \\
\hline $\begin{array}{l}\text { pridie kls } \\
\text { madii }\end{array}$ & 30 & lun & $\begin{array}{l}\text { Real de } \\
\text { Orihuela }\end{array}$ & r. 340 f. $4 \mathrm{v}$ & $\begin{array}{l}\text { Jaime II inicia asedio del } \\
\text { castillo y villa de Orihuela }\end{array}$ \\
\hline
\end{tabular}

\section{Particular interés y utilidad del presente Itinerario}

La condición itinerante de Jaime II de Aragón, en perenne desplazamiento por lugares diferentes dentro y fuera de su corona, persiguiendo siempre escuchar y atender in situ personalmente los problemas diversos de sus gentes, lo convirtió en un incansable y permanente viajero, consiguiendo que tan sorprendente movilidad real dote a su Itinerario de un interés excepcional. Ya que gracias al mismo podemos situar al monarca, en cada uno de los momentos de su largo reinado y de modo especial en el quinquenio dedicado a la conquista y anexión del reino castellano de Murcia a su corona (1296-1301), el que hoy ocupa a este Congreso particularmente, en el espacio y tiempo precisos, a través de la doble datación crónica y tópica consignadas en los documentos reales.

Tal Itinerario suministra además el adecuado marco cronológico y toponímico a un sinfín de actos oficiales del monarca, referentes ya a privilegios, cartas, donaciones, franquicias, sanciones, fueros e instituciones reales, etc., que por uno u otro motivo carecen a veces en su transmisión documental, publicada o inédita aun, de la correspondiente datación crónico-tópica, posibilitándonos de esta suerte la identificación 
correcta de la misma, pues tanto una como otra se complementan entre sí y yuxtaponen habitualmente.

Por cuanto la ausencia, desaparición y falta de una de ellas, puede llegar a suplirse por la presencia documental de la otra, llegando por su medio a la identificación de entrambas o a la exclusión a veces de una de ellas, por no encajar de forma alguna en el contexto, debiendo en este caso ser desechada y sustituida por la datación correcta. Por tal procedimiento puede llegarse a averiguar una fecha no expresada, así como el lugar de datación tampoco referido, a base tan solo de la referencia explicitada de una de las dos dataciones aludidas. Ya que la datación crónica puede averiguarse, aunque no vaya expresada en el texto, por la datación tópica y viceversa, no pocas veces.

Por todo ello la utilidad del Itinerario de Jaime II de Aragón es manifiesta para situar al monarca en un momento dado en el lugar preciso, aunque éste no se halle expresado en el documento y otro tanto puede afirmarse acerca de la fecha exacta en que se emanó un documento real, aunque ésta no figure en el mismo.

$Y$ en no pocos casos el presente Itinerario nos ayudará a detectar el error de ciertos autores, incluso consagrados, en la datación ya crónica o tópica equivocadas. La presentación de algunos ejemplos concretos nos ayudará positivamente a comprender mejor la utilidad del susodicho Itinerario.

Resulta que un error en la datación crónica de un determinado documento, conlleva idéntico error en la datación tópica también, como ocurre al ilustre historiador y documentalista ANTONIO BENAVIDES ${ }^{6}$, quien, al fechar los documentos 81 y 84 en los días 4 y 18 de febrero respectivamente del año 1297, en Alhama de Segura (Murcia), el primero, y en Valencia el segundo, se equivoca de lleno, por hallarse Jaime II de Aragón en las fechas referidas en Roma, huésped del papa Bonifacio VIII, para negociar el espinoso asunto de la devolución del Reino de Sicilia a la Iglesia Romana, a cambio de la infeudación papal de los Reinos de Córcega y Cerdeña, feudatarios a su vez de la Sede Apostólica.

El citado historiador no tuvo en cuenta la datación por la Era Incarnationis, en el Estilo florentino, de la cancillería de Aragón, debiendo añadir una unidad a la cifra del año en cuestión, como ya es sabido, desde el uno de enero al veinticuatro de marzo, por lo que el año correcto documentado por él no es el 1297, sino el 12987. Lo que hubiera podido obviarse fácilmente de haber tenido a la mano el Itinerario de Jaime II. De donde se desprende la importancia y utilidad del mismo.

$Y$ otro tanto ocurre con el no menos conocido archivero del ACA, MANUEL DE BOFARULL Y DE SARTORIO ${ }^{8}$, al asignar erróneamente también la datación tópica de Valencia al documento citado, cuando escribe: «Dat. Valentie VI idus madii an. dni. $M$

6 Crónica de Fernando IV de Castilla. // Colección diplomática, Madrid, 1860, dctos. 81 y 84.

7 "Datum in castro de Alfama pridie nonas februarii an.dni. M CC XC VII» ACA, C, reg. 256, f. 182r y reg. 195, f. 123r: «Dat. Valentie XII kls martii an. dni. M CC XC VIl», fechas correspondientes al 4 y 18 de febrero del año 1298.

8 Colección de Documentos Inéditos de la Corona de Aragón (CODOIN-ACA), vol. 42, dło. 375 , Barcelona, 1876. 
CC XC VIIl', datación que no se ajusta a la realidad histórica, por encontrarse Jaime II aquel 10 de mayo del año 1298, no en Valencia, sino en Barcelona ${ }^{9}$.

De igual modo yerra otro destacado historiador, de la estirpe benemérita de los BOFARULL, de nombre ANTONIO DE BOFARULL I BROCA ${ }^{10}$, al situar a Jaime $\|$ en Valencia, el dos de febrero del año 1299, cuando en realidad por aquellas fechas se encontraba bien lejos de allí, en Milazzo (Sicilia), dirigiendo la operación militar, ya aludida, contra su hermano, Federico $\mathrm{III}^{11}$.

Este mismo autor escribe en otro lugar, erróneamente también, que Jaime II de

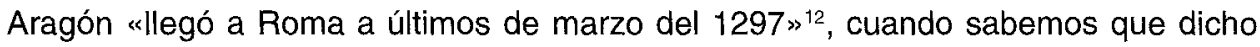
monarca se hallaba en la Ciudad Eterna ya desde dos meses antes, llegando a la misma el 14 de enero de aquel año exactamente ${ }^{13}$, convirtiéndose en huésped de Bonifacio VIII, como ya queda expuesto anteriormente.

De forma similar yerra otro ilustre historiador alemán, JOHAN VINCKE ${ }^{14}$, al asignar al documento 10 de su Colección Documental la doble datación crónica y tópica equivocadas: Valencia, 13 de marzo del 1317, cuando en realidad el documento citado reza exactamente: Dat. Valentie III idus martii anno domini M CCC XVIII5, datación que corresponde no al año 1317 , sino al $1318^{16}$. Y por lo demás Jaime II en la fecha apuntada por VINCKE no se hallaba en Valencia, sino en Barcelona ${ }^{17}$. Lapsus en el que no hubiera incurrido por cierto el citado historiador, de haber tenido a la vista el ITINERARIO de dicho monarca, por donde se desprende la importancia y necesidad de la publicación del mismo.

La utilidad de este Itinerario resulta manifiesta para la identificación precisa de un determinado topónimo, cual es el caso de la confusión por un destacadísimo investigador de la historia de este período ${ }^{18}$, del Castillo de Lort (EI LLOR, La Segarra, Lérida) con el Castillo de Lorca (Murcia), al escribir: «Sembla que Jaume II tornà a fer una breu escapada al regne de Mùrcia a primers de juliol de 1297; el 4 d'aquest mes almenys era en el setge de Lorca». Dato éste imposible de encajar en el Itinerario del monarca aragonés, a quien resultaba materialmente imposible realizar un desplazamiento de

9 «Datum Barchinone sexto idus madii an. dni. M CC XC VIII», ACA, C, reg. 324, f. 276v.

10 Historia crítica de Cataluña, Barcelona, 1876, vol. IV, pp. 64-65.

11 «Dat. in portu Melacii IV nonas februarii anno domini M CC XC VIII», ACA, C, reg. 265, f. 119r.

12 Historia crít. de Cataluña, IV, p. 51.

13 «Dat. Rome XIX kalendas februarii anno domini M CC XC VI», ACA, C, reg. 321, f. 55r.

14 "Königtum und Sklaverei im aragonischem Staatenbund während de 14. Jahrhunderts", Spanische Forschungen der Görresgesellschaft, erste Reihe. Gesammelte Aufsätze zur Kulturgeschichte Spaniens, 25 Bund, Münster im Westfallen, 1970, p. 46.

15 ACA, C, reg. 215, f. 260r.

16 Por seguir la cancillería de Aragón, como ya es sabido, la Era Incarnationis, en el Estilo Florentino, debiendo añadirse una cifra más al año expresado, desde el 1 de enero al 24 de marzo.

17 «Dat. Barchinone III idus martii anno domini M CCC XVI», ACA, C, reg. 162, f. $6 r$.

18 FERRER I MALLOL, M" Teresa, "Notes sobre la conquesta del Regne de Murcia per Jaume II (1296-1304)", Homenatge a la memòria del Prof. Dr. EMILIO SAEZ. Aplec d'Estuis dels seus deixebles i col-laboradors, Barcelona, 1989, Universidad de Barcelona. Centre d'Estudis medievals de Catalunya. Institució Milà i Fontanals (CSIC), pp. 27-44; p. citada, 39. 
más de 700 kilómetros, desde el castillo aludido de El Llor, en la provincia de Lérida, al de Lorca, en la región meridional de la provincia de Murcia, en un mismo día, ya que el 4 de julio de aquel año está poniendo sitio al castillo leridano de Lort, El Llor ${ }^{19}$, al igual que el día anterior, 3 de julio ${ }^{20}$, y el día $5^{21}$, resultándole al monarca de todo punto imposible encontrarse el mismo día en dos lugares tan distantes entre sí. La existencia del Itinerario de Jaime II de Aragón hubiera hecho imposible tal confusión.

Es útil así mismo también el presente Itinerario para resolver las dudas de algún notable medievalista ${ }^{22}$, quien, al situar la documentación a Jaime II en un mismo día (14 mayo 1296) en dos lugares distintos, si bien cercanos, a menos de 10 kilómetros de distancia, la villa de Orihuela y el castillo murciano de Monteagudo $^{23}$, y al esotro día (el 15), de nuevo en Orihuela ${ }^{24}$, y al siguiente (día 16) en Murcia ${ }^{25}$, atribuye a un error del escribano la datación tópica del día 14 ante el castillo de Monteagudo ${ }^{26}, 10$ que a decir verdad no implica necesariamente un lapsus del escribano, si se tiene en cuenta la distancia tan reducida entre ambos lugares (10 kms. escasos), perfectamente recorribles en una misma jornada (menos de $20 \mathrm{kms}$. con ida y regreso).

Puede ayudarnos también este Itinerario a corregir en determinados casos los datos biográficos de un personaje célebre en la historia peninsular, como es el caso puntual del arzobispo de Tarragona, D. Rodrigo, cuyo fallecimiento lo apunta erróneamente un ilustre historiador ${ }^{27}$, el 16 de diciembre del año $1307^{28}$, fecha que en modo alguno se ajusta a la realidad histórica, ya que Jaime II le dirige una carta personal, muchos meses después, el 21 de agosto del $1308^{29}$, demostración fehaciente de que regía aun por estas fechas la metrópoli de Tarragona.

Tras esta breve exposición de los tres puntos fundamentales enunciados, los que

19 «Dat. in obsidione castri de Lort IV nonas julii anno domini M CC XC VII», ACA, C, reg. 264, f. 36v. Carta de Jaime II al veguer de Don Juan Manuel en Villena, Pedro Escriba.

20 «Dat. in obsidione castri de Lort V nonas julii an. dni. M CC XC VII». ACA, C, reg. 252, f. 167r. Carta a su hermano, Federico III de Sicilia.

21 "Dat. in obsidione castri de Lort III nonas julii anno domini M CC XC VII». ACA, C, reg. 252, f. 167r. Jaime II a su hermano Federico III de Sicilia.

22 FERRER I MALLOL, o.c., p. 35.

23 Ibid.: «el 14 de maig el rei era a Oriola, però el mateix dia era també al campament daval del castell de Monteagudo, a la vora de Mùrcia».

24 ACA, C, reg. 340, f. 87r: «Dat. Oriole idibus julii anno domini M CC XC Vl».

25 ACA, C, reg. 340, f. 69v: «Dat. en la Huerta de Murcia, juxta castrum de Montagut, XVI dias andados del mes de mayo en el anyo de nuestro senyor M CC noventa e seys".

26 FERRER I MALLOL, O.c., p. 35: «Sembla, doncs, que hi ha d'haver un error de datació a la carta del dia 14 de maig, que situa al rei a Monteagudo", $Y$ añade seguidamente una conclusión a nuestro juicio erronea: «perquè de fet el monarca no es mogué d'Oriola fins el 15 o el 16 de maig», ya que la doble datación tópica, alterna, consignada, se explica perfectamente por la distancia tan corta referida, salvable muy bien una y más veces en un solo día.

27 EUBEL, Hierarchi catholica Medii Aevi, Münster im Westfallen, reed. 1913, I, p. 479.

28 "Obiit Rodericus archiepiscopus Tarrachonensis (1307 decembris 16)», 0.c., ibid.

29 «Roderico archiepiscopo Tarrachonensi... Dat. Valentie XII kalendas septembris anno domini M CCC octavo", ACA, C, reg. 140, f. 150r. 
a su vez estimamos más destacables en nuestro Itinerario documental, sobre la conquista por Jaime II de Aragón del reino castellano de Murcia, a saber: su importancia y necesidad, la metodología y mecánica seguidas en su elaboración, más el interés y utilidad del mismo, nos permitimos añadir a continuación como un muestrario o selección del mismo, a modo de colofón de todo lo expuesto, un Anexo final.

En dicho anexo o Itinerario parcial de Jaime II hemos procurado dispensar particular atención a la campaña militar del monarca aragonés en la conquista del mencionado reino murciano, durante el período aproximado de cinco años, desde febrero del 1296 a enero del 1301, tratando de subrayar los sucesos de mayor interés al respecto.

Hemos estimado oportuno también presentar a modo de preludio anticipado de dicha conquista, las gestiones realizadas por Jaime II ante los alcaides castellanos de los castillos de Alicante (Nicolás Pérez de Murcia), de Orihuela (Pedro Roiz de Sant Cebrian) del castillo murciano de Monteagudo (Juan Fernández de Gomariz) y del castillo de Cartagena (Sancho Díez de Bustamante), con una antelación de casi nueve meses antes de dicha conquista, encaminadas directamente a conseguir de los mismos la entrega pacífica de los castillos citados, con la prestación consiguiente del homenaje vasallático debido, en consecuencia a la violación por su rey, Sancho IV, del Pacto o Concordia de Monteagudo-Soria (29 noviembre 1291).

En carta personal a los susodichos alcaides castellanos advertía Jaime II, el 5 de agosto del año $1295^{30}$, que, ante una eventual respuesta negativa suya, procedería a arrebatarles por la fuerza las fortalezas citadas, en claro presagio de la guerra que tal recusación iba a desencadenar entre las coronas de Castilla y Aragón.

No hemos descuidado tampoco en nuestro Itinerario el dedicar cierta atención al periplo marítimo, que efectuó por tres veces, en este período, Jaime II, a Roma y curia papal de Bonifacio VIII (enero-abril 1297); al Reino de Nápoles y corte de Carlos II de Anjou, su suegro (julio-agosto 1298 y marzo-junio 1299); y al Reino de Sicilia (agostodiciembre 1298 y enero-marzo y julio-agosto 1299), en miras a recabar de su hermano, Federico III de Sicilia, la renuncia a aquel reino en beneficio de la Iglesia Romana, en base al ya citado Tratado de Anagni (1297), por entrañar todo ello el alejamiento del monarca de Aragón del escenario peninsular, dentro del período estudiado (12961301), en la campaña militar emprendida por Jaime II para someter el reino castellano de Murcia e incorporarlo a su corona.

30 Consúltense dichas cartas en el citado Anexo documental o Itinerario parcial de Jaime II de Aragón, en la fecha indicada. 


\section{ANEXO DOCUMENTAL}

Itinerario parcial de Jaime II de Aragón (1296-1301)

Mes Lugar Ref dtal. Regesta

\section{Año 1295}

\section{Agosto}

5

Barcelona

ACA CRD Jaime II caj. $1, \mathrm{n}^{\circ} 250^{31}$

5

Barcelona

ACA CRD Jaime II

caj. $1, n^{\circ}=247$

5

5

5

Barcelona

5

Barcelona
CRD Jaime II

caj. $1, n^{\circ} 237$

caj. $1, \mathrm{n}^{\circ} 248$

CRD Jaime III

caj. $1, n^{\circ} 277^{32}$

CRD Jaime II

caj. $1, n^{0} 238^{33}$
CRD Jaime II
Orden al alcaide del castillo de Orihuela, Pedro Roiz de Sant Cebrian, de entregarle la fortaleza por violación de su rey, Sancho IV, de la Concordia de Monteagudo -Soria- 29 nov. 1291.

Carta en idéntico sentido al alcaide del castillo murciano de Monteagudo, Juan Fernández de Gomáriz.

Ídem al alcaide del castillo de Cartagena, Sancho Díez de Bustamante.

Ídem al alcaide del castillo de Alicante, Nicolá Pérez de Murcia.

Ídem al alcaide aragonés del castillo de Fita, en rehén de Castilla, Rodrigo Martínez de Guadalajara, liberándolo del vasallaje al rey castellano.

Id. al alcaide aragonés de los castillos de Cervera, Alfaro y Agreda, Alfonso de Haro, en liberación del vasallaje a Castilla ${ }^{34}$.

31 ESTAL, J.M. del, El reino de Murcia bajo Aragón, 1296-1304/5, l/1, Alicant 1985, pp. 109-110 y $12-15$.

32 ESTAL, El reino de Murcia bajo Aragón, 1/1, pp. 11-20.

33 Ibid., pp. 11-15.

34 Actitud que entraña una abierta determinación aragonesa de ruptura con Castilla y por ende una resuelta disposición de Jaime II a ocupar los citados castillos murcianos, si sus alcaides respectivos no se aprestaban a acatarlo como legítimo soberano suyo y su señor natural.

Era en suma la declaración anticipada de guerra a Castilla por el reino de Murcia, donado reiteradamente en tres ocasiones sucesivas (1289 y 1296) por el infante don Alfonso de la Cerda a la corona de Aragón. ESTAL, J.M. del, Conquista y anexión de la tierras de Alicante al reino de Valencia por Jaime // de Aragón, Alicante, 1982, pp. 160-171 y 325-329. 


\section{Año 1296}

\section{Febrero}

17 Cetina (Z) ACA, C, r. 252 f. $230 r^{35}$ Jaime II notifica a Bernat de Sarrià donación del reino de Murcia por inf. d. Alfonso de la Cerda y el ultimatum al rey Fernando IV de entregarlo en 15 días so pena de ocuparlo por la fuerza.

Notifica Jaime II a su consejero, Bernat de Sarrià, y a Pedro de Llibià, baile general del reino de Valencia, el envío a Murcia de Bernat Merçer para ganar ciertos prohombres a la causa de Aragón ${ }^{36}$.

22 Zaragoza Reg. 252 f. 231 r

Orden a Bernat de Sarrià de hacer armar diez galeras en astilleros de Valencia, Barcelona y Mallorca $^{37}$.

$22^{38}$ Zaragoza Reg. 252 f. $130 \mathrm{v}-131 \mathrm{r}$ Reg. 340 f. $63 r-v$

Encomienda Jaime II a Berenguer de Vilaragut y Ramón de Manresa asunto galeras en Barcelona; a Pedro de Foces en Mallorca y al canciller, Ramón Despont, en Valencia, donde era obispo.

\section{Marzo}

4 dom $^{\circ}$ Zaragoza Reg. 103 f. $264 r$

Dat. Cesarauguste IV nonas martii a.d. MCCXCV.

Jaime II ruega al papa Bonifacio VIII el abono de las $12.000 \mathrm{lib}$. tournesas por renunciar al reino de Sicilia en favor de la Iglesia Romana.

35 FERRER I MALLOL, o.c., pp. 29, 42-43; ESTAL, El reino de Murcia..., I/2, Alicante, 1990, pp. 16-18.

36 FERRER I MALLOL, o.c., pp. 29 y $42-43$.

37 Ibid., pp. 30 y 43-44; ESTAL, ibid., pp. 17-18.

38 Queremos significar aquí que en los años bisiestos, los día 24 y 25 de febrero, al contar este mes con 29 días, se explicitan en la calendación romana bis VI kls martii (el 24) y VI kls martil (el 25) respectivamente, derivando de aquf la denominación de año bisiesto. 
Jaime II interesa al ra'is de Crevillente, Muhammad ibn Hudayr, en la conquista del reino de Murcia por su condición de vasallo de Aragón.

Jaime II pudo entrar en Alicante este mismo día aunque no haya constancia documental.

Este día recibió ya el monarca de Aragón el homenaje vasallático de Guillem de Folch en casa de Ramon Ça Costa en Alicante ${ }^{39}$.

Gestión de una tregua de 26 días con el merino mayor de D. Juan Manuel, Sancho Ximenes de Lanclares, en miras a su acatamiento como soberano del reino de Murcia $^{40}$.

Nombramiento de Bernat Bonivery como notario público "totius regni Murcie» ${ }^{41}$.

Reg. 340 f. 5r-6r Donación a Guillem Durfort, consejero real, de un heredamiento en La Daya, entre Almoradí y Orihuela, confiscado anteriormente al castellano Fernando Pérez de Guzmán por su rebeldía contra Aragón ${ }^{42}$.

Reg. 194 f. 214r-v Se confirma la donación anterior en premio a los servicios prestados a Jaime I, su abuelo, a Pedro III, su padre, y a Alfonso III, su hermano ${ }^{43}$.

Conmina al inf. D. Alfonso de Portugal y esposa, Da Violante Manuel, a acatarlo como legítimo soberano del reino de Murcia.

39 A partir de esta fecha procedió ya Jaime II a la provisión de los cargos públicos de alcaide, baile y justicia en el castillo y villa de Alicante en los caballeros Pedro de Urtx, Raimundo de Capiath y Berenguer de Puigmoltó. ESTAL, El reino de Murcia..., 1/1, pp. 21-22.

40 ESTAL, ibid., pp. 74-77.

41 ibid., pp. 26, 113 not. 1.

42 Ibid., pp. 113-116.

43 Ibid., pp. 116-118. 
29 dom Almoradí Reg. 340 f. 3v

29

Almoradí (A) ACA, C, r. 340 f. 51 r

30

Almoradí

Reg. 340 f. $288 \mathrm{r}$

$30 \mathrm{lu}$

Huerta de

Reg. 340 f. $52 r$

Almoradí

30

Real ante

Reg. 340 f. $288 \mathrm{r}$

Orihuela

\section{Mayo}

1

Real ante Reg. $340 \mathrm{f.} 11 \mathrm{r}$

Almoradí

1

Real ante

Orihuela
Ordena al consell de Guardamar efectuar entrega de todo el grano acopiado en la iglesia del lugar ${ }^{44}$.

Al expirar la tregua con D. Juan Manuel el 19 mayo ruega Jaime II a su merino mayor, Sancho Ximenes de Lanclares elija lugar de encuentro con su enviado, Pedro de Llibià, para entregarle la plaza de $\mathrm{Elche}^{45}$.

Donación a su portero real, Bernat de Genebret, de varios heredamientos en Murcia, confiscados a Fernando Pérez Cantador, mayordomo del adelantado por Castilla en el reino de Murcia, D. Juan Sánchez de Ayala, por su rebeldía contra Aragón ${ }^{46}$.

Jaime II acoge bajo su tutela real al noble don Juan García de Loaysa, as como a los hombres y mujeres de los castillos de Bañeres y Petrer, señoríos suyos ${ }^{47}$.

Sienta este día sus reales Jaime II ya dentro del propio término de Orihuela ${ }^{48}$.

Inicio del cerco de Orihuela desde el campamento ante Almoradi ${ }^{49}$.

Acampa Jaime II ante el castillo y villa de Orihuela ${ }^{50}$.

44 Ibid., pp. 120-121. Jaime II nombró alcaide de Guardamar a Galcerand de Rosanes, quien desempeñó un papel sobresaliente en la recaudación de vituallas para la tropa aragonesa ocupada en la conquista del reino castellano de Murcia.

45 ESTAL, El reino de Murcia..., l/1, p. 76.

46 ibid., pp. 121-123.

47 Ibid, , 1/2, Alicante, 1990, pp. 28-29: «Dat. in orta de Almoradi in regno Murcie».

48 «Dat. in casis termino de Oriola in Regno murcie tertio kls madii anno domini M CC XC VI». ESTAL, ibid., $1 / 1$, dto. 30 , p. 121.

49 "Dat. in castris apud locum de Almoradino»; "Dat. in orta de Almoradino» ibid.

50 «Dat, in obsidione de Oriola kls madii anno domini M CC XC VI», ibid 
Al ra'is de Crevillente, Muhammad ibn Hudayr, que permita a los mudéjares de Alicante, allí refugiados, en su señorío regresar a la villa alicantina con sus haberes ${ }^{51}$.

$8 \mathrm{ma}$ Asedio de Reg. 340 f. $29 \mathrm{r}$ Orihuela

10

$\begin{array}{ll}\text { Asedio de } & \text { ACA, perg. } 642 \\ \text { Orihuela } & \text { de Jaime II }\end{array}$

11

Orihuela

Reg. 194 f. $238 r$
Al portero real, Bernat de Genebret, que provea de vituallas al alcaide del castillo de Callosa de Segura, Bernat de Pujades ${ }^{52}$.

El alcaide del castillo de Abanilla (MU), Miguel García, acata soberanía de Jaime II en el reino de Murcia, respetando el señorío de su señor, Guillem de Rocafull ${ }^{53}$.

Jaime II dentro ya de Orihuela confirma a sus vecinos el título de propiedad de sus casas y hacienda.

11 Orihuela

12

Orihuela

Reg. 340 f. $35 r$

Arch.Mun.Orih. (AM
Lib. priv., MS 2588, fols. $15 r-16 r$

Pleito-homenaje de la corporación municipal de Orihuela, 38 miembros, a Jaime II, en la iglesia del Salvador, acatándolo como legítimo soberano y su señor natural ${ }^{54}$.

Donación a Berenguer de Liminyana, vecino de Orihuela, de los lugares de Xacara y Xacarella por los servicios prestados.

Orihuela Reg. 340 f. 58r

Reg. 340 f. $66 \mathrm{~V}$

Conmina al alcaide del castillo murciano de Monteagudo, Juan Fernández de Gomáriz, a hacerle entrega del mismo.

13 dom $^{\circ}$ Orihuela Reg. 340 f. $66 \mathrm{~V}$

Al alcaide del castillo de Alicante, Pedro de Urtx, que imponga a un cautivo castigo ejemplar por insultos a los vecinos del lugar.

Constituye bailes de la villa de Orihuela a los vecinos Pedro Rosselly y Guillem Parratge con el compromiso de acopiar el mayor volumen posible de vituallas ${ }^{55}$.

51 «Dada en el çerco de Oriola, quatro dias andados del mes de mayo en el anyo de nostre senyor M CC XC sies». ESTAL, El reino de Murcia bajo Aragón..., 1/2, pp. 29-30.

52 Ibid., $1 / 1$, p. 32.

53 TORRES FONTES, Juan, CODOM II, nº CXIX, pp. 121-122; ESTAL, ibid. l/1, pp. 35-36.

54 TORRES FONTES, ibid. ESTAL, ibid. $1 / 1$, pp. 129-132. El castillo en cambio de Orihuela, regido por el alcaide Pedro Roiz de Sant Cebrian, no se rindió hasta más tarde, el 21 de junio, jueves, tras cumplirse el plazo acordado de 40 días. ESTAL, ibid., pp. 40-41.

55 ESTAL, El reino de Murcia..., 1/1, pp. 158-159. 
$14 \mathrm{lu}$

Real ante Reg. 340 f. $66 r$
Monteagudo

15

Orihuela

Reg. 340 f. $63 \mathrm{v}$

16

16

Huerta de

Murcia ante

castillo de

Monteagudo

16

Ídem

Reg. 340 f. $66 \mathrm{r}-\mathrm{v}$

17

Ídem

Reg. 25 f. 282 r

17

Ídem
Reg. 340 f. $69 \mathrm{v}$

Al caballero Gonzalo de Fontana sobre el cobro del quinto de las cabalgadas en el término de Orihuela ${ }^{56}$.

A los alcaides de Alicante y Guardamar, Raimundo de Urtx y Galcerand de Rosanes que no estorben el regreso a casa del caballero Exerio Pérez de Oza con seis hombres suyos ${ }^{57}$.

Al alcaide del castillo de Alicante, Raimundo de Urtx, y al justicia del mismo, Raimundo Castellan sobre el indulto a Julián y Pedro Martínez de Alcañiz, vecinos del lugar ${ }^{58}$.

Se congratula ante el rey de Granada, Muhammad II, por la paz firmada entre ambos, dos dias antes ${ }^{59}$.

Salvoconducto real a favor del adelantado por Castilla en el reino de Murcia, Juan Sánchez de Ayala, para que pueda abandonar indemne aquel reino con su mujer e hijos, en el plazo de diez días ${ }^{60}$.

Acta de sumisión y vasallaje del ra'is de Crevillente, Muhammad ibn Hudayr, a Jaime II como soberano legítimo del reino de Murcia $^{61}$

Prórroga del plazo primitivo de 30 días a 42 para entregarle el alcázar intraurbano de Murcia, regido por el alcaide Martín Fernández debiendo librarlo a su enviado Bernat de Sarrià ${ }^{62}$.

56 Ibid., p. 164. El mismo día 14 se desplazó Jaime II de Orihuela al asedio del castillo de Monteagudo, regresando de nuevo a Orihuela, debido a la corta distancia de apenas diez kilómetros.

57 ESTAL, ibid., pp. 43-44.

58 La datación tópica de los días 16 al 18 de mayo se expresa indistintamente por la cancillería de Aragón en los términos siguientes: "dat. apud Montem Acutum"; "dat. en la huerta de Murcia juxta castrum de Montagut»; "escrita en la orta de Murcia prop lo castell de Montagut»; «dat. in campis juxta castrum de Monte Acuto»; "dada en la orta de Murcia prope locum de Monteagut»; "dat. in orta Murcie juxta locum qui dicitur Montagut». ESTAL, ibid. I/1, pp. 167-183; 1/2, pp. 44-46.

59 ESTAL, ibid. $1 / 1$, pp. 169-170.

$60 \mathrm{Ibid} . \mathrm{I} / 2$, pp. $44-45$.

61 lbid., pp. 50 y $176-179$.

62 ESTAL, El reino de Murcia..., l/1, pp. 180-181. 
Salvoconducto a favor del alcaide del castillo de Murcia Monteagudo, Juan Fernández de Gomáriz, para llegarse indemne a su presencia para negociar la entrega del castillo ${ }^{63}$.

$19 \mathrm{sab}$ Murcia

Reg. 340 f. $74 r$ y $75 r$

Tras la entrevista con Juan Fernández de Gomáriz, Jaime II no obtuvo aún la capitulación del castillo de Monteagudo, hasta 21 de junio, pudiendo ocupar sin embargo la ciudad de Murcia en este día ${ }^{64}$.

20 dom $^{\circ}$ Murcia

Reg. 340 f. $76 \mathrm{v}$

Jaime II pide al noble casteliano don Juan García de Loaysa, tenente del castillo de Petrer y vasallo del infante D.Alfonso de Portugal y de su esposa $D^{a}$ Violante Manuel, que lo acate como soberano del reino de Murcia y señor suyo natural ${ }^{65}$.

20 dom $^{\circ}$ Murcia

Reg. 340 f. $76 r$

A petición del ra'is de Crevillente, Muhammad ibn Hudayr, Jaime II acogió bajo su tutela real «a todos los moros del Regno nuestro de Murcia»66.

$21 \quad$ Murcia Reg. 340 f. $79 r$

Embajada aragonesa del abad de Foix, Jofré de Cruïlles, ante D. Alfonso de la Cerda, «rey de Castiella».

Mayo

22

Murcia Reg. 340 f. $80 \mathrm{v}$

Embajada de Jaime II en el franciscano fray Pedro ante el concejo de Lorca para recabar su acatamiento y vasallaje.

63 Ibid., pp. 182-183.

64 La entrada de Jaime II en la ciudad de Murcia no supuso la rendición del castillo intraurbano - Alcazar-Kibir, cuyo alcaide Martín Fernández no capitularía tampoco aquel día y fue objeto de varios emplazamiento o treguas hasta mediados de junio, fecha en que acató la soberanía del monarca aragonés. ESTAL, ibid., pp. 40-42 y 61-64.

65 ESTAL, ibid., pp. 67-69 y 188-189. En idénticos términos dirigió sendas cartas al citado infante D. Alfonso de Portugal y esposa.

66 Por estas mismas fechas habían acatado a Jaime ll como rey legítimo de Murcia y señor suyo natural los lugares Murcianos de la cuenca alta y media del Segura, más los lugares del valle alto y medio de su afluente, el río Mundo, destacando entre otros Hellín, Calasparra, Cieza, Ricote, Archena, Lorquí, Ceutí, Las Alguazas y Molina Seca, acogiéndolos de igual modo bajo su protección real el monarca aragonés. ESTAL, ibid., p. 48. 
Nombra a Jaime Pérez, señor de Segorbe, su hermano, procurador general de reino de Mur$\mathrm{cia}^{67}$.

Reg. 231 f. $58 \mathrm{r}$

Constituye al ra'is de Crevillente, Muhammad ibn Hudayr, juez ordinario de los mudéjares del reino de Murcia ${ }^{68}$.

$24 \quad$ Murcia

Reg. 340 f. $107 \mathrm{v}-108 \mathrm{r}$

Confirma la posesión de un horno de pan y cier ta casas al arráez de la Arrixaca de Murcia, Abenhayça.

28

Sitio de Reg. 340 f. $258 \mathrm{~V}$

Mula (MU)

Inicia el asedio de la villa y castillo de Mula, capitulando al día siguiente ${ }^{69}$.

30

Mula

Reg. 340 f. $112 r$

Al proveedor de vituallas de la casa real, Guillem Columer, que le haga llegar del mejor caldo de la tierra ${ }^{70}$.

31 ju Mula

Reg. 340 f. $115 \mathrm{r}$

Homenaje del alcaide del castillo de Mula, Pedro Zapata, al rey de Aragón ${ }^{71}$.

A punto de cumplirse la tregua acordada con D.Juan Manuel (próximo 2 junio, sábado) ordena al procurador general, Jaime Pérez, que proceda contra él y su señorío de Elche con máxima dureza ${ }^{72}$.

\section{Junio}

Alhama (MU)

67 ESTAL, El reino de Murcia..., l/1, pp. 197-198.

68 "ut sitis judex sarracenorum Regni nostri Murcie». Ibid., pp. 51-52.

69 lbid., pp. 199-200.

70 «de meliori vino quod inveneritis», ibid., p. 200.

71 Poco después tornó a rebelarse de nuevo este alcaide contra Aragón no logrando someterlo Jaime II hasta el 1303, FERRER I MALLOL, "Notes sobre la conquesta del regne de Murcia...», pp. 36 y 40 .

72 "post predictam diem sabbati facietis et fieri faciatis malum et dampnum quodcunque poteritis in loco Eltx et hominibus habitantibus in eo et bona eorum», ESTAL, ibid., pp. 201 y 74-85. 
Inicio del asedio al castillo y villa de Lorca, que Lorca (MU)

3 dom $^{\circ} \quad$ Sitio de Lorca Reg. 340 f. 284 r

Confirma al alcaide de la ciudad de Cartagena, Romeu de Morimond, en su cargo, por entregarle la plaza antes de caducar la tregua el 27 de mayo $^{74}$.

Constituye delegado real al caballero, Ferran Garçes de Rueda, para recibir el homenaje de los moros de los castillos de Axpe, Monóvar y Chinosa y jurarlos al ra'is de Crevillente, Muhammdad ibn Hudayr ${ }^{75}$.

$9 \mathrm{sab} \quad$ Murcia Reg. 340 f. $139 \mathrm{v}$

Al rey de Nápoles, Carlos II de Anjou, su suegro, que facilite a Galcerand de Montoliu llegar hasta el almirante Roger de Lauria en el Reino de Sicilia

10 dom $^{\circ}$ Murcia

Reg. 340 f. $132 r$

Al conde de Urgel, Ermengol, prohibiéndole enrolarse en la armada de Federico III de Sicilia $^{76}$.

Orihuela

Reg. 340 f. 130 r

Al rey de Nápoles, Carlos II de Anjou, comunicándole el envío a Cataluña de una galera armada para reclutar ballesteros por Federico III de Sicilia, lo que no puede tolerarse por contravenir el Tratado de Anagni ${ }^{77}$.

12 Sitio de Elche Reg. 340 f. $129 \mathrm{~V}$

Tras el incumplimiento de las treguas firmadas por el noble D.Juan Manuel, decide Jaime II sitiar la villa de Elche.

73 No volviendo a reanudar el sitio hasta mediados de diciembre del 1300, mes en que lograría su capitulación definitiva. ESTAL, "Nuevos datos sobre la capitulación y conquista aragonesa de Lorca», Homenaje al Prof. D. JUAN TORRES FONTES, Universidad de Murcia, 1987, pp. 431-464.

74 ESTAL, El reino de Murcia..., 1/1, pp. 70-73. El alcaide del castillo de Cartagena, Sancho Díaz de Bustamante, en cambio no acató la soberanía de Aragón hasta más tarde, el 23 de julio siguiente.

75 Ibid., p. 60. Este mismo día recibió Jaime II también el homenaje del noble D. Juan García de Loaysa por la tenencia del castillo de Petrel. FERRER I MALLOL, o.c., p. 38.

76 Por contravenir ala Paz de Anagni del 1395, ESTAL, ibid., pp. 206-207.

77 lbid., pp. 209-210. 
$16 \mathrm{sab}$ Sitio de Elche Reg. 340 f. 122r

18

Sitio de Elche Reg. 340 f. $150 \mathrm{~V}$

21 ju Sitio de Elche Reg. 340 f. 182v-183r Jaime II confirmó a su alcaide, Pedro Roiz de

24 dom $^{\circ}$ Sitio de Elche Reg. 340 f. 168r, 180r

29 Sitio de Elche Reg. 340 f. $182 v$-183r

25 Sitio de Elche Reg. 340 f. $171 \mathrm{r}$

$30 \mathrm{sab}$
Sitio de Elche Reg. 340 f. 185 r, 187r Sant Cebrian, en el cargo.

A su consejero real, Bernat de Sarrià, que impida a Carroç el embarque en el puerto ilicitano del Al-Ajub embarcar con sus hombres armados rumbo Sicilia en ayuda de Federico III, su hermano ${ }^{78}$.

Al procurador general de reino de Murcia, Jaime Pérez, que esté en Orihuela el día 21, jueves, por expirar ese día la tregua dada al alcaide de su castillo, Pedro Roiz de Sant Cebrian, para hacerse cargo del mismo ${ }^{79} 80$.

Dat.al setge de Eltx XXIV dies andados del mes de juny de l'anyo de $n$. seynor M CC XC VI.

Al baile general del reino de Murcia, Bernat Colomer, que, transcurrido sin éxito el plazo dado, le envíe una relación de los castellanos insumisos para proceder a la incautación de sus bienes en dicho reino ${ }^{81}$.

Al noble Jaspert, vizconde de Castellnou, al frente de la tropa aragonesa ante Villena, que inflija daños a las tierras de D. Juan Manuel por su insumisión ${ }^{82}$.

Dat. in obsidione de Eltx pridie kalendas julii anno domini M CC XC VI, asedio que se prolongaría hasta la firma de una Tregua por 7 años el 27 de julio ${ }^{83}$.

78 ESTAL, El reino de Murcia..., l/1, pp. 213-214.

79 Ibid., pp. 215-216.

80 Ibid., pp. 41-42.

81 lbid., pp. 218-219.

82 «e que talets e cremets allí tot ello que potets e que hi fasats con maior tala e maior mal puscats", ESTAL, Ibid., pp. 79-80.

83 Ibid., pp. 71-85 y 212-241. 


\section{Julio}

1 dom $^{\circ} \quad$ Sitio de Elche Reg. 194 f. $246 \mathrm{r}$

Reg. 340 f. $191 \mathrm{r}$

3

Sitio de Elche Reg. 340 f. $191 \mathrm{v}$

$11 \mathrm{mi}$ Sitio de Elche Reg. 340 f. $183 \mathrm{v}$

$18 \mathrm{mi}$ Sitio de Elche Reg. 340 f. 240r, 152r

$23 \mathrm{lu}$

$27 \mathrm{vi}$

Sitio de Elche Arch. Cat. Valencia, perg. 0567

$29 \mathrm{dom}^{\circ}$ Elche

Reg. 340 f. $266 \mathrm{r}$

30

Murcia

Reg. 340 f. $269 r$
Donación de amplios heredamientos al caballero Ferran Garçes de Rueda por los muchos servicios prestados.

Al justicia de la ciudad de Murcia, Pedro Jiménez de Spilonga, que, mientras se compila el Fuero Nuevo, siga sirviéndose de los fueros alfonsinos y donde éstos no basten, recurra a los furs valencianos ${ }^{84}$.

Confirma a la ciudad de Cartagena sus fueros.

Al arzobispo de Tarragona, D. Rodrigo, que cuide de restaurar el orden en la metrópoli.

Compromiso formal de Jaime II de no separar jamás el castillo y villa de Alicante de la corona de Aragón ${ }^{85}$.

Tregua por siete años entre Jaime II y D. Juan Manuel hasta que cumpla 21 años (9.V.1303) ${ }^{86}$.

Jaime II dentro ya de Elche: «Dat. in Eltxio IV kalendas augusti anno dni.M CC XC Vl».

Jaime II se traslada a Murcia para proseguir la conquista del reino.

\section{Agosto}

4 sab Murcia

4

Orihuela

Reg, 194 f. 236v
Reg. 263 f. 114r, 280v Tras la confirmación a Murcia de todos sus fueros abandona la capital.

Al baile general del reino de Murcia, Bernat Colomer, que dé posesión de un heredamiento en Beni-Totana (MU) a Hugo de Solanis, confiscado a Aldolza López, dama de cámara de la reina $\mathrm{D}^{\mathrm{a}}$ María de Molina ${ }^{87}$.

84 ESTAL, El reino de Murcia..., 1/1, pp. 119-120; ÍDEM, «El fuero y las -Constitutiones regni Murcie- de Jaime II de Aragón, 1296-1301 ", Anales de la Universidad de Alicante, $H^{a}$ Medieval, 8, 1991, pp. 19-56.

85 ESTAL, El reino de Murcia, l/1, pp. 225-228. En la misma fecha confirmó a la villa de Alicante todos los fueros y libertades de que disfrutara hasta la fecha, ibid. pp. 223-225.

86 Ibid., pp. 80-85.

87 lbid., p. 246. 
$5 \mathrm{lu} \quad$ Alicante

12 dom $^{\circ}$ Valencia

Reg. 263 f. $1+5 v$

16 ju Valencia

Reg. 104 f. $34 r$

21 ma Valencia

Reg. 194 f. $248 \mathrm{~V}$

1 ju Barcelona Reg. 194 f. 313r-v

18 dom $^{\circ}$ Cadaqués Reg. 321 f. $10 \mathrm{~V}$

puerto (GE) Dat. in portu de

Cadaqués
Esta primera quincena del mes la dedicó Jaime Il a preparar su viaje marítimo a Roma, donde residió por espacio de más de tres meses, huésped del papa Bonifacio VIII.

Al obispo de Zaragoza, D. Ximeno de Luna, que dote al clérigo Raimundo de un beneficio eclesiástico en el arciprestazgo de Teruel para ayudarlo en sus estudios en Montpellier ${ }^{90}$.

88 ESTAL, El reino de Murcia, 1/1, pp. 246-247; ÍDEM, «Erección por Jaime II de una feria en Alicante», Revista IDEA (Instituto de Estud. Alicantinos), 16, 1975, pp. 153-174; IDEM, "Mercados y ferias medievales en Alicante...", IDEA, 35, Alicante, 1982, pp. 35-38.

89 Permaneció el monarca aragonés en la capital del Turia por espacio de casi dos meses, hasta el 13 de octubre, reg. 263 f. 156v: «Dat. Valentie III idus octobris anno dni. M CC XC VI».

90 Zarpa del puerto de Cadaqués Jaime II rumbo la corte papal de Bonifacio VIII en Roma y Anagni, adonde no llegó hasta el 14 de enero del 1297, tocando los los puertos de Port Vendres (Vallespir, r. 321 f. 20r, el 4 dic.); el día 8 en Aigües Mortes (Gard, Languedoc, r. 321 f. 21r); el 11 en Marsella (r. 321 f. 21v); el 21 «in portu de Olig» (r. 321 f. 23v); el 28 dic. en Alfic (r. 321 f. 22 r); el 1 de enero de 1297 ante Orbetello, en la Toscana (dat. in mari ante portum de Sancto Stefano, r. $321 \mathrm{f.} 22 \mathrm{v}$ ); el 2 en Civitavèchia (dat. in Civitate Veteri, r. 321 f. 22v) y por fin Roma, el 14 de enero del 1297 (dat. Rome XIX kls februarii an. dni. M CC XC VI, 1297). 


\section{Enero}

16 ma Roma

Reg. 321 f. $25 \mathrm{v}$

20 dom $^{\circ}$ Roma

Reg. 321 f. 30 r

Reg. 321 f. $32 v$

\section{Febrero}

5 ma Roma

7 ju Roma

Reg. 321 f. $34 v$

\section{Marzo}

3 dom $^{\circ} \quad$ Roma

Reg. 321 f. $42 r$

10 dom $^{\circ}$ Roma

Reg. 321 f. $45 r$

19 ma Roma

reg. 321 f. $49 v$

31 dom $^{\circ}$ Roma
Al almirante Roger de Lauria que acuda a su presencia en Roma para tomar el mando de la armada de Aragón contra Federico III de Sicilia, por lo que le otorga «in feudum castrum et villam de Cocentayna" (A).

Nombra al jurisperito aragonés, Juan, notario real y jefe de la escribanía de la Çalmedina de Zaragoza en régimen vitalicio.

A Romeu de Morimond que tome a su mando las 12 galeras armadas del rey de Nápoles, Carlos II de Anjou, y se sume a las de Aragón, surtas en Gaeta.

Nombra a Bernat de Sarrià almirante de toda la armada de la corona de Aragón ${ }^{91}$.

Al procurador general del reino de Murcia, Jaime Pérez, que dé posesión de cierto heredamiento en Orihuela a Pedro de Verduno.

Al maestre de la orden del Templo en Aragón y Cataluña, Berenguer de Cardona, que no permita la extracción de vituallas del término de Peñíscola (CS).

A Bernat de Sarrià, almirante de la armada de la corona, que ponga al frente de alguna de las galeras contra Sicilia a Bernardo de faro.

Sustituye a Gay Sexmundi cónsul de catalanes en Pisa por Simone Arlotti.

91 "Almirante regnorum nostrorum Aragonum, Maiorice, Valentie et Murcie ac comitatus Barchinone, remoto quolibet alio in dicto officio admirantie constituto", ACA, C, reg. $321 \mathrm{f} .34 \mathrm{v}$. 
4 ju Roma

Reg. 341 f. $2 r-6 r$

5

Roma

Reg. 321 f. 54r-v

7 dom $^{\circ} \quad$ Roma

8

Civitavecchia (I)

13 sab Civitavecchia Reg. 321 f. 59r

$18 \mathrm{ju}$

In mari entre Reg. $321 \mathrm{f} .60 \mathrm{r}$

Civitavecchia

y Marsella

$25 \mathrm{ju}$ Barcelona Reg. $311 \mathrm{f} .207 \mathrm{r}$

\section{Mayo}

$7 \mathrm{ma}$ Barcelona reg. 324 f. $231 \mathrm{v}$

$23 \mathrm{ma}$ Lérida Reg. 108 f. 34v
Infeudación papal de Jaime II por Bonifacio VIII del reino insular de Córcega y Cerdeña, a cambio de la cesión del reino de Sicilia a la iglesia de Roma, gobernado a la sazón por Federico III'.

Al rey de Nápoles, Carlos II de Anjou, su suegro, so bre el matrimonio de su hijo, Roberto, duque de Calabria, con la infanta Yolanda, hermana del rey deAragón ${ }^{93}$.

Ultimo día de estancia en Roma de Jaime II de Aragón $n^{94}$.

Al podestà y senado pisano sobre ciertas irregularidades financieras del mercader catalán, Berenguer Mata, vecino de Montblanc ( $\mathrm{T}$ ).

Encarga al almirante Ro ger de Lauria negociar con Federico III la devolución del reino de Sicilia a la iglesia romana.

Al maestre de la Orden del Hospital de San Juan de Jerusalén, Guillem de Villaroers, acerca del negocio confiado.

Jaime II está de nuevo en esta ciudad, de regreso de su periplo marítimo a Roma.

Acerca de ciertos disturbios originados por la sucesión en el condado del Pallars.

Jaime II nombra al abad del monasterio cisterciense de Santes Creus $(T)$ capellán mayor de la Capilla Real.

92 Comprometiéndose Jaime II a llevar a cabo dicha empresa con las armas, si fuera preciso, como ocurrió de hecho. SALAVERT Y ROCA, Vic., Cerdeña y la expansión mediterránea de la corona de Aragón, 1297-1314, II, Madrid, 1956, pp. 22-30.

93 Ibid., pp. 31-32.

94 «Dat. Rome VII idus aprilis anno dni. M CC XC VII», r. 321 f. 60 r. 
Junio

$5 \mathrm{mi} \quad$ Lérida

Reg. 252 f. $163 v$

Al papa Bonifacio VIII sobre el asunto del reino de Sicilia y la resistencia de su hermano, Federico III, a renunciar al mismo.

$18 \mathrm{ma}$ Vila de Reg. 195 f. $29 \mathrm{~V}$

Estarás (L)

De camino Jaime ll a poner sitio a los castillos de La Cuba (HU) y de El Llor (L) $)^{95}$.

$20 \mathrm{ju} \quad$ Sitio del Reg. 311 f. 19r castillo de

"dat. in obsidione castri de La Cuba (p.j. Barbastro-Huesca) XII kls julii anno dni. M CC XC VII".

22 sab Sitio al

Reg. 311 f. 30r

castillo de

El Llor (L)

Inicia el asedio a este castillo de Lort (El Llor, La Segarra, L) ${ }^{96}$.

Julio

$2 \mathrm{ma}$

Sitio al

Reg. 195 f. $63 \mathrm{r}$

astillo de

El Llor

Prosigue Jaime II el asedio al castillo de El Llor (castrum de Lort) iniciado el 22 de junio pasa$\mathrm{do}^{97}$.

3 Sitio castillo Reg. 252 f. 167r

El Llor

4

Sitio El Llor Reg. 264 f. 36v

Al veguer de D. Juan Manuel en Villena, Pedro Escriba $^{99}$.

5 vi Sitio castillo Reg. 252 f. $157 \mathrm{r}$

El Llor

A Federico III acerca de su obligada renuncia al reino de Sicilia a tenor del Tratado de Anagni ${ }^{100}$.

7 dom $^{\circ} \quad$ Sitio al

Reg. 252 f. $167 v-168 r$

castillo de

El Llor

Continúa el asedio al castillo de El Llor ${ }^{98}$.

Expone a su hermano Federico III las causas de empuñar las armas contra él, de no acceder al beneplácito del papa Bonifacio $\mathrm{VIII}^{101}$.

95 «Dat. apud villam de Estars XIV kls julii an. dni. M CC XC VII».

96 «Dat. in obsidione castri de Lort X kalendas julii an. dni. M CC XC VII», reg. 311 f. 30r. Asedio que mantuvo Jaime II por casi dos meses, sin abandonar la provincia de Lérida, hasta el 29 de agosto del mismo año, cuando lo encontramos ya en Huesca.

97 «Dat. in obsidione castri de Lort VI nonas julii an. dni. M CC XC VIl», reg. 195 f. 63 r.

98 "Dat. in obsidione castri de Lort V nonas julii an. dni. M CC XC VII".

99 "Dat. in obsidione castri de Lort IV nonas julii an. dni. M CC XC VII».

100 SALAVERT Y ROCA, o.c., II, pp. 30-32.

101 Ibid., pp. 32-34. 
25 ju Lérida

Reg. 264 f. $51 \mathrm{r}-52 \mathrm{v}$

Reg. 252 f. $174 \mathrm{v}$

\section{Agosto}

$19 \mathrm{lu}$

Lérida

Reg. 264 f. 70r

25 dom $^{\circ}$ Lérida

Reg. 264 f. 72 r

Reg. 311 f. $172 \mathrm{r}$

Reg. 311 f. $195 \mathrm{v}$

$14 \mathrm{sab}$ Zaragoza Reg. 109 f. $311 \mathrm{v}$

Reg. 195 f. $70 v-71 \mathrm{r}$

\section{Septiembre}

1 dom $^{\circ}$ Huesca

Desde el 29 agosto reside Jaime II en esta ciudad hasta el día 6 de septiembre.

Ruega al Capítulo provincial de la Orden de Predicadores en Valencia que sustituya en Murcia los frailes castellanófilos por otros fieles a la causa de Aragón.

Permaneció el monarca en esta ciudad casi dos meses, hasta el 16 de noviembre.

\section{Octubre}

6 dom $^{\circ}$ Teruel

Reg. 106 f. 15r-v

Notifica al juez eclesiástico de Tarragona, Fernando Juanes, el levantamiento papal de la excomunión al veguer de la ciudad, Bernat de Fonollar.

$31 \mathrm{ju}$ Teruel Reg. $106 \mathrm{f.61 \textrm {V }}$
Ordena al obispo de Cartagena, D.Rodrigo, retirar el entredicho al justicia de Murcia, Pedro Jiménez de Spilonga ${ }^{102}$.

102 Incurso en la pena eclesiástica por haber detenido dentro del recinto sagrado al reo de homicidio, Pedro Sánchez, pese a haberse ajustado en tal acción al vigente fuero de Murcia. 


\section{Noviembre}

3 dom $^{\circ} \quad$ Teruel

Reg. 899

(erróneamente de

Pedro IV) f. 150r
Jaime II concede a la villa de Alicante franquicia de lezda y peaje por contribuir a la obra de la Torre del Molinell, lugar de control aduanero entre Valencia y Alicante ${ }^{103}$.

\section{Noviembre}

$16 \mathrm{sab}$ Valencia Reg. 264 f. 140r

Jaime II fija su residencia en esta ciudad, donde permanecerá el resto del año, hasta mediados de enero siguiente.

19

Valencia Reg. 324 f. $243 r$

Convenciones entre Carlos II de Nápoles y Jaime II de Aragón, su yerno, contra Federico III de Sicilia ${ }^{104}$.

\section{Año 1298}

\section{Enero}

$14 \mathrm{ma}$ Jijona (A) Reg. 195 f. $117 \mathrm{~V}$

Jaime II reanuda de nuevo la campaña militar en el reino de Murcia para someter los lugares rebeldes de Alhma, Lorca, Mula y Alcalá etc.

$18 \mathrm{sab}$ Asedio al Arch.R.V., castillo de reg.c. $611 \mathrm{f} .198 \mathrm{r}$ Alhama (MU)

Nombra al caballero de Verona, Lorenzo de Scala alcaide del castillo de Almizra

\section{Febrero}

$1 \mathrm{sab}$ Sitio al castillo de Alhama

$3 \mathrm{lu}$ Castillo de Alhama

$6 \mathrm{ju} \quad$ Murcia
Reg. 196 f. $131 \mathrm{r}$

Reg. 256 f. $30 \mathrm{v}-31 \mathrm{v}$

Prosigue el asedio al castillo de Alhama: «in obsidione castri de Alfama» y otorga franquicia de ancoraje a las naves que atraquen en el puerto de Alicante.

Al rey de Granada, Muhammad II, congratulándose de la capitulación del castillo de Alahma ${ }^{105}$.

Confirma a Muhammad ibn Hudayr en el cargo de ra'is de Crevillente ${ }^{105}$.

103 ESTAL, El reino de Murcia, 1/1, pp. 274-278; IDEM, Documentos inéditos de Alfonso $X$ el Sabio y del infante su hijo D. Sancho, Alicante, 1984, pp. 28-38.

104 MIQUEL ROSELL, F.J., Regesta de Letras Pontificias del archivo de la corona de Aragón, Barcelona, 1948, no 295, pp. 157-158.

105 ESTAL, ibid., pp. 289-290.

106 Ibid., pp. 290-291. 
AHN, Aledo, caj. 50, no 10

Traslado del a.1757
Agradece a los comendadores santiaguistas de Ricote, Fernando Pérez, de Cieza, Juan Martínez y de Aledo, Pay Ferrándiz, los servicios prestados a la causa de Aragón ${ }^{107}$.

\section{Abril}

18 vie Sant Mateu del Maestrat (CS)

Reg. 264 f. 305v Hace alto en este lugar en su camino de regreso a Barcelona.

25 vie Barcelona Reg. 319 f. 13r

De vuelta a esta ciudad Jaime II prepara su próximo viaje marítimo extrapeninsular a Nápoles y Sicilia adonde zarpará el 10 de junio, con ánimo de cumplimentar la voluntad papal, aunque sin éxito, por espacio de año y medio, no regresando a Barcelona hasta octubre del 1299.

\section{Año 1299}

\section{Mayo}

6 ma Nápoles Reg. 265 f. 178r

Residió aquí Jaime II, con su esposa Da Blanca de Anjou, huésped de su suegro, Carlos II, cuatro meses (24.7-14. 8, 1298 y 21.3-26.6, 1299), preparando y ejecutando expedición militar al reino de Sicilia $(26.6-14.8,1299)$, pero $\sin$ éxito ${ }^{108}$.

\section{Junio}

19 vie Anagni (I)

Arch.Vat, reg.49 f.179

Huésped Jaime II del Papa Bonifacio VIII obtuno ${ }^{\circ}$ CIIII ${ }^{109}$ vo subsidios diocesanos para la empresa militar de Sicilia.

29 lu Amalfi (I) Reg. 113 f. $175 \mathrm{r}$

Reanuda navegación hacia Sicilia, notificando a su suegro, Carlos II de Anjou, la salida.

107 TORRES FONTES, Juan, CODOM, II, núm. CXXVIII, pp. 132-133; ESTAL, ibídem, pp. 292-293.

108 No explicitamos con detalle este periplo marítimo de Jaime II, por rebasar los límites del tema de esta Comunicación, remitiendo al lector interesado en ello a nuestro ITINERARIO completo de este monarca, que esperamos salga en breve su publicación.Durante su estancia en Nápoles dio a luz su esposa al futuro Alfonso IV de Aragón.

109 Edic. DIGART, G., Les Registres de Boniface VIII, II, Paris, 1884 1939, no 3083, col. 420. 
Julio

9 ju Cabo de ACA, CRD Jaime II

Orlando $\quad n^{\circ} 387$

(Sicilia)

\section{Agosto}

4 ma Puerto de Reg. 265 f. $215 \mathrm{r}$ Milazzo (I)

$13 \mathrm{ju} \quad$ Castillo de Reg. 197 f. 30v San Marco (I)

$31 \mathrm{lu} \quad$ Pozzuoli (I) Reg. 265 f. 225v

\section{Septiembre}

3 ju

Puerto de Reg. 265 f. 222r
S. Felice de
Circeo (I)

13 dom $^{\circ}$ Puerto de Pisa (I)

19 sab Puerto de Tolon (FR)

25 vie Puerto de Reg. 265 f. $241 v$

l'Aigle,

Marsella (FR)

\section{Octubre}

1 ju Castillo de Reg. 265 f. 267r Blanes (GE)

$3 \mathrm{sab}$

Barcelona

reg. 265 f. $232 r$
Notifica a Bonifacio VIII haber arribado al caput de Orlando y derrotado a Federico III.

Comunica al duque de Calabria, Roberto de Anjou, el triunfo habido en el cabo Orlando de Sicilia sobre Federico III.

«Dat.in litore maris prope castrum Sancti Marciidus augusti an.dni.M CCXC IX»"110.

Camino de regreso a Barcelona.

En el golfo de Gaeta, rumbo a España.

Reg. 265 f. 225v Dat. apud portum Pisanum idus septembris an.dni. M CC XC IX, donde permaneció una semana, hasta el día 16.

Reg. $265 \mathrm{f.262r}$ In mari in Provincia (Provenza) in portu de Oliulas, hoy Toulon, XIII kis octobris a.d. MCCXCIX.

In portu vocato de Aquila in Provincia (Provenza) hoy Carry le-Rouet al NW de Marsella.

Dat. in mari ante castrum de Blanis (Blanes, Gerona).

Arribo final de Jaime II a Barcelona, tras el peripło marítimo de casi año y medio por Nápoles y Sicilia.

110 Ante las persistentes dificultades de someter a su hermano, Federico III y devolver aquel reino de Sicilia a la iglesia romana, Jaime II decidió abandonar la empresa militar y emprender el regreso a Barcelona. 
Al procurador general de los reinos de Valencia y Murcia, Jaime de Jérica, encomendándole los noble oriolanos Juan de Rocafull e hijo, Guillem. Jaime II residirá ahora en Barcelona por más de medio año, hasta el 23 de abril del 1300 .

23 vie Barcelona Arch.Mun.Elche (AME) La reina Dª Blanca de Anjou confirma fueros y Arm.2, codice, franquezas de Orihuela ${ }^{111}$. $\mathrm{n}^{\circ} \mathrm{XXXV}, \mathrm{f} . \mathrm{XXXIXr}$

\section{Año 1300}

\section{Mayo}

15 dom $^{\circ}$ Lérida

Reg. 332 f.51v

Nueva convocatoria de los nobles de Aragón por Jaime II para someter los pocos castillos rebeldes del reino de Murcia, sobretodo los de Lorca, Mula y Alcalá entre otros.

$31 \mathrm{ma}$ Lérida

Reg.332 f. 53r, 57v

Orden a los barones de Aragón de presentarse el próximo 10 de julio en Visiedo y Calamocha, con sus hombres de armas, para someter los focos rebeldes murcianos.

\section{Junio}

28 ma Teruel

Reg. 332 f.57r-v

Al noble don Pedro Cornell que acuda a renirse con él en Visiedo con todos sus hombres de armas.

$\begin{array}{ll}\text { Julio } & \\ 1 \text { vie Teruel } & \begin{array}{l}\text { Reg. } 266 \text { f. } 258 r-259 r \\ \text { Reg. } 332 \text { f. } 59 r\end{array}\end{array}$

Al procurador general de Aragón, Lope Ferrench de Luna, que esté en guardia contra ataque eventual castellano de su frontera.

15 vie Daroca Reg. 332 f. 73 r

Convocatoria del procurador general de Aragón, Lope Ferrench de Luna, a las cortes de aragón el 8 de agosto próximo.

111 ESTAL, El reino de Murcia, l/1, pp. 299-300. 


\section{Agosto}

$1 \mathrm{lu}$

Alagón (Z) Reg. 332 f. 68r-69r

$17 \mathrm{mi} \quad$ Zaragoza Reg. 332 f. $75 \mathrm{r}$

\section{Septiembre}

16 vie Zaragoza Reg. 332 f. 70r

\section{Octubre}

9 dom $^{\circ}$ Calatayud(Z) Reg. 325 f. 3r-v

$12 \mathrm{mi}$ Calatayud Reg. 116 f. 196v

12

Calatayud Reg. 332 f. 112r-v

Reg. 332 f. $120 \mathrm{v}$

4 vie Valencia

$$
\text { Reg. } 332 \text { f. } 120 \mathrm{~V}
$$

6 dom $^{\circ} \quad$ Valencia

Reg.332 f. $122 r$

f. $120 \mathrm{~V}$

f. $121 \mathrm{r}-\mathrm{v}$
Al procurador de Aragón, Lope Ferrench de Luna, que esté preparado para rechazar un ataque eventual de Fernando IV a su frontera.

Mandato a los maestres de las ordenes Militares del Templo, Santiago, Calatrava y castellanía sanjuanista de Amposta de hallarse vigilantes contra una incursión castellana inminente.

Al sobrejuntero de Zaragoza, Rodrigo, que tenga bien alertados a los vecinos de Velilla de Ebro contra un eventual ataque castellano.

A los colectores de la gabelas de la sal en Zaragoza que hagan saber las condiciones de compraventa de aquel producto en un bando.

Al procurador general del reino de Murcia, Bernat de Sarrià, que esté en guardia contra un ataque eventual castellano.

A los feuadatarios de la corona de aragón que acudan a Valencia con sus huestes el 11 de noviembre.

Al noble Juan García Jofré de Loaysa, lugarteniente del infante D. Alfonso de Portugal en los castillos de Elda y Novelda, que provea de los hombres armados solicicitados por Bernat de Sarrià ${ }^{112}$.

Resuelto Jaime II a sofocar de una vez los focos aún rebeldes a su causa, los castillos de Lorca, Mula y Alcalá, entre otros, convocó un cuantioso contingente armado en Cocentaina (A) bien equipados de caballos, armas, aparatos de guerra y provisiones para cuatro meses.

112 ESTAL, El reino de Murcia, l/2, Alicante, 1990, p. 111. 
6 dom $^{\circ}$ Valencia Reg.332 f. 125r-v

$8 \mathrm{ma}$ Valencia Reg. $332 \mathrm{f.} 121 \mathrm{r}$

$9 \quad$ Valencia

reg. 332 f. $121 r$

13 dom $^{\circ}$ Valencia

reg. 332 f. $125 r$

$17 \mathrm{ju} \quad$ Valencia Reg. 332 f. $123 \mathrm{r}$ f. $124 \mathrm{~V}$

18 dom $^{\circ}$ Valencia
Reg. 332 f. $124 \mathrm{v}$
En iguales términos se dirigió a los consells valencianos de Museros, Massamagrell, Vilafames, Massanassa, Albaida y Xirivella, ordenándoles poner los hombres de armas solicitados a disposicición de Bernat de Sarrià ${ }^{113}$.

A los comendadores santiaguistas de Cieza, Ricote y Aledo en el reino de Murcia, señores Juan Martínez, Fernando Pérez y Pay Fernández respectivamente, que urjan el pago del monedaje a sus vecinos y entregarlo a Pedro Escribano, para ayuda campaña militar murciana $^{114}$.

A todos los oficiales del reino de Valencia que activen con diligencia la mayor leva posible de hombres de armas para sofocar los focos aun rebeldes del reino de Murcia $^{115}$.

Igual mandato de leva a los lugares valencianos de Alcira, Játiva, Gandía, Pego, Beniopa, Pop, Gallinera y Ebbo, a través de su portero Miguel del Real, provistos también de víveres para cuatro meses.

Al justicia, jurados y comunidad de Ademuz (V) que recluten hombres de armas, bien equipados de caballos y aparatos de guerra, con provisiones para cuatro meses y se sumen en Alicante al grueso militar real el uno de diciembre próximo.

Al procurador general del reino de Murcia, Bernat de Sarrià, que haga una leva de hombres de armas en Alicante, debidamente equipados, de los que lleve él la mitad y el resto lo sumará el monarca al grueso de su expedición personal.

113 Ibid., pp. 112-113.

114 ESTAL, El reino de Murcia, l/2, pp. 114-115.

115 Ibid., pp. 115-116. 


\section{Diciembre}

$17 \mathrm{sab}$ Real ante Reg. $293 \mathrm{f.} 1 \mathrm{r}$ Lorca (MU)

18 dom $^{\circ}$ Lorca

Reg. 293 f. $17 r-25 r$

19 Lorca

Reg. 293 f. $4 r$

$24 \mathrm{sab}$ Lorca

Reg. 293 f. $19 \mathrm{v}$

27 ma Lorca

Reg. 293 f. $25 r$

$28 \mathrm{mi} \quad$ Lorca
Conmina Jaime II al alcaide del castillo de Lorca, Nuño Pérez, a la entrega de la Torre Alfonsí o del homenaje, tras haberse consumido los plazos otorgados de 50 y 60 dias, so pena de confiscar a los defensores sus casas $y$ haciendas ${ }^{116}$.

Acta de Capitulación del castillo y villa de Lorca, suscrita por su alcaide, Núño Pérez, y el de la villa, López Fernán dez, aunque en precario ${ }^{117}$.

Compromiso de Jaime II ante el maestre santiaguista, Juan Osores, de acojer bajo su tutela regia las encomiendas de Ricote, Cieza y Aledo, durante la conquista del reino de Mur$\mathrm{cia}^{118}$.

Al comendador santiaguista de Moratalla, Juan Alvarez, emplazándolo a prestarle el homenaje debido antes de 20 días por hallarse enclavada su encomienda dentro delreino de Mur$\mathrm{cia}^{119}$.

Pendiente Jaime II del abastecimiento de Lorca, impone a sus oficiales que no estorben a sus en viados regios, Jaime Peregrín y Juan Cayrat, descargar sus viandas en los puertos de Cartagena, Aguilas, Guardamar y Alicante ${ }^{120}$.

Ultimatum de Jaime II al alcaide del castillo, Nuño Pérez, y demás defensores del mismo, de entregarlo al dia siguiente, 29 , so pena de males mayores ${ }^{121}$.

116 ESTAL, "Nuevos datos sobre la capitulación y conquista aragonesa de Lorca", Homenaje al Prof. don JUAN TORRES FONTES, Universidad de Murcia, 1987, I, pp. 432 y 441; ÍDEM, El reino de Murcia, l/2, p. 122.

117 Se comprometían ambos alcaides a desalojar y entregar villa y castillo con sus tres torres, la principal o Alfonsina, la del Espolón y la de Guillen Pérez de Pina en el plazo máximo de 50 días, compromiso que incumplió particularmente el susodicho alcaide del castillo Nuño Pérez, por lo que Jaime II hubo de actuar en consecuencia, ESTAL, "Nuevos datos sobre la capitulación...», pp. 432$433,442-447$.

118 Ibid., pp. 433-434 y 447-448; ÍDEM, El reino de Murcia, I/2, p. 130.

119 Ibid., pp. 435 y $455-456$.

120 Ibid., pp. 437 y 456-457; ESTAL, El reino de Murcia, l/2, p. 140.

121 Ibid., pp. 436-437 y 457. Y la amenaza surtió por fin su efecto. 
Jaime II confirma al alcaide, López Fernández, de la villa de Lorca y su concejo los fueros de que disfrutara hasta la fecha ${ }^{122}$.

\section{Año 1301}

\section{Enero}

3 ma Murcia

Reg. 332 f. $127 \mathrm{v}$

Ante la dilación de entrega de la Torre Alfonsina del castillo de Lorca por su alcaide Nuño Pérez, Jaime II hubo de reclutar nuevos combatientes, acudiendo a la leva de mudéjares en el medio y bajo Vinalopó ${ }^{123}$.

5 ju Murcia

Reg. 332 f. $128 r-v$

Próxima la fecha cuaresmal de la celebración de cortes en Cataluña, Jaime II notifica al conde de Ampurias, Ponç Hugonis el aplazamiento de las mismas a causa de hallarse ocupado en la dura empresa de someter los focos aun rebeldes de la Torre Alfonsina de Lorca, del castillo de Mu la y el de Alcalá ${ }^{124}$.

$11 \mathrm{mi} \quad$ Murcia

Reg. 332 f. $127 \mathrm{v}$

Al noble D.Juan García de Loaysa que haga llegar cuanto antes a las fuerzas sitiadoras del castillo de Mula los mudéjares convenidos de Elda y Novelda ${ }^{125}$.

122 Sin hacer otro tanto al alcaide del castillo de Lorca, Nuño Pérez, por haber incumplido el ultimatum de entregarle la Torre Alfonsina o del Homenaje, ESTAL, El reino de Murcia, 1/2, pp. 143144; ÍDEM, «Nuevos datos sobre la capitulación...», pp. 436-437 y 469-460.

123 En este sentido convocó a filas, urgiéndoles incorporarse a la tropa concentrada frente a los focos Murcianos aún rebeldes de los castillos de Lorca, Mula y Alcalá, a los mudéjares de las aljamas sarracenas de Elda, Novelda y Elche, ESTAL, El reino de Murcia, I/2, p. 145.

124 Ibid., pp. 146-147. En idénticos términos se dirigió a los condes del Pallars, de Urgel y a otros numerosos nobles catalanes.

125 Ibid., p. 148: "Dehim vos e manam vos que vos manets per vostra letra als dits moros que els que vinguen en la dita ost de Mula sens tota tregua... Dada en Murcia XI dies anats del mes de gener en l'ayn damunt dit». 


\section{Año 1301}

\section{Enero}

13 vie Murcia

Reg. 118 f. 2r

Al procurador general del reino de Valencia, Jaspert, vizconde de Castellnou y comandante en jefe de la tropa asediante el castillo de Lorca, que, concluyendo la tregua otorgada al alcaide del castillo de Lorca, Nuño Pérez el domingo próximo (15.l.1301), deberá urgir la entrega de la Torre Alfonsina sin próroga alguna ulterior ${ }^{126}$.

$14 \mathrm{sab}$ Murcia Reg. 332 f. 129r

En la espera de que el alcaide del castillo de Lorca, Nuño Pérez, le haga entrega por fin de la Torre del homenaje del mismo o Alfonsina, despacha Jaime II numerosas cartas a los procuradores, bailes, justicias y demás oficiales de la corona que apoyen el acopio de viandas con destino al castillo y villa de Lorca $^{127}$.

17 ma Murcia Reg. 332 f. $149 \mathrm{~V}$

A los ricos-hombres y prelados del reino de Aragón que proporcionen a sus enviados, $\mathrm{Pe}$ dro de Roda y Juan de Roquefort el volumen mayor posible de vituallas para los castillos recien sometidos y necesitados del reino de Murcia.

16-20 enero

Núño Pérez entendió que no podía dilatar más la entrega de la Torre Alfonsina y la entregó.

126 «por aquesto decimos e mandamos vos que requirades a Nuño Pereç e los otros sobreditos, dia domingo primero que viene (15 enero), en el qual se cumplen los ditos $X V$ dias, que nos desemperen la dita Torre Alfonsia, segunt puesto es en las ditas convinencias. Essi ellos un otro alongamiento entendieren, no ge les consintades de un dia ni de una ora, antes queremos e mandamos firmement e expressa de sos pena de la nostra graçia e merçé, que tantost pensedes de enantar contra las rahenas e contra Nuño Pereç e los otros sobditos sin ninguna mercé, assi como contra aquellos que crebantan fe e prometimiento que fazen a seynor, a que a otros sea siempre escarmiento e exiemplo». ESTAL, El reino de Murcia, l/2, pp. 148-149; ÍDEM, «Nuevos datos sobre la capitulación...», p. 440.

127 ESTAL, El reino de Murcia, pp. 150-155. 


\section{Año 1301}

\section{Enero}

$18 \mathrm{mi} \quad$ Murcia Reg. 332 f. $149 \mathrm{r}$

Orden de Jaime II al portero real, Juan de Roquefort, que se haga cargo con el repostero de la reina, $D^{\text {a }}$ Blanca de Anjou Pedro de Roda, del transporte de las viandas acopiadas en Aragón para avituallamiento de los castillos necesitados del reino de Murcia ${ }^{128}$.

$21 \mathrm{sab}$ Murcia Reg. 198 f. $244 \mathrm{r}$

Tras la entrega por fin de la Torre Alfonsina de castillo de Lorca por su alcaide, Nuño Pérez, el rey de Aragón procedió a confirmar a la villa y castillo de Lorca todos sus fueros y libertades de los que disfrutara anteriormente bajo la soberanía castellana, en premio al juramento de vasallaje y fidelidad prestados ${ }^{129}$. Concluía así el asedio más largo y duro de Jaime II en la conquista del reino castellano de Murcia, restándole tan solo por someter las plazas de Mula y Alcalá, y muy pocas otras de menor importancia.

128 ESTAL, El reino de Murcia, 1/2, p. 155.

129 «laudamus etconfirmamus vobis universis et singulis fidelibus vestris, fidelibus nostris habitatoribus... castri et ville de Lorcha et terminorum suorum et vestris successoribus in perpetuum privilegia, libertates, franchitates et inmunitates, foros ac bonos usus et bonas consuetudines ac etiam donationes, quas obtinuistis a regibus Castelle, antecessoribus nostris in regno Murcie, prout hec in cartis quas inde habetis plurimum continetur et prout ex ipsis melius usi estis. Mandantes per presens privilegium nostrum procuratori regni predicti, necnon justiciis, bajulis eiusdem et universis aliis officialibus nostris... quod hanc, approbationem et confirmationem nostram firmam habeant, teneant et observent ac inviolabiliter faciant observari...», ESTAL, El reino de Murcia, 1/2, pp. 156-157. 